\title{
Weaving the Web Word - from Myth to Modernity
}

\author{
Karen Simpson Nikakis \\ Deakin University, Melbourne, Victoria, Australia \\ karen.simpsonnikakis@deakin.edu.au
}

\begin{abstract}
The discovery, development or invention of new objects and phenomena by humankind, requires a new set of words to be coined or adopted to describe it. This is also true of the Information Communication Technology (ICT) world. Words are not neutral, regardless of which dialect or language they occur in. They carry with them associations and connotations based on their previous applications and alliances, and augmented by their shapes, sounds, rhymes and rhythms. The subtext that word choice creates, while often not recognised or acknowledged, is important in considering how communication operates in, and shapes Information Technology (IT) environments. Many words that are now embedded in the ICT lexicon continue to be informed by these earlier meanings, some of which, in the English lexis, are drawn from myths. The vernacular of the ICT lexis reflects its openness to new ideas, the nature of its users, its English language roots and its Western cultural origins. This contributes to a particular communication style. But such lexis can prove problematic for non-English speaking background users and/or those from different cultures. As the ICT vocabulary continues to evolve, these language and cultural underpinnings are coming under challenge, suggesting a language and cultural future very different to the past. This in turn, will create a subtext that affects all users.
\end{abstract}

Keywords: connotation, denotation, nomenclature, lexis, coining, subtext, portmanteau, neologism, phonetic, alliteration, Power Distance, Uncertainty Avoidance, ICT, lexicon

\section{Introduction}

O'Grady, Dobrovolsky and Katamba (1996) suggest that “...human language must be creative allowing novelty and innovation in response to new thoughts, experiences, and situations" (p. 1). This paper explores the communicative aspect of language subtexts that can be created in response to the "new thoughts, experiences and situations" of Information Communication Technologies (ICT's). It also raises questions about the future implications of such subtexts. In $A$ short history of the Web (1995), Robert Cailliau describes how he and Tim Berners-Lee attempted to coin a "catching" name for the system that they and others had developed. Cailliau is "determined" that the name should not "again be taken from Greek mythology" and when Berners-Lee suggests the term World-Wide Web, Cailliau admits to liking it "very much," (with the

Material published as part of this publication, either on-line or in print, is copyrighted by the Informing Science Institute. Permission to make digital or paper copy of part or all of these works for personal or classroom use is granted without fee provided that the copies are not made or distributed for profit or commercial advantage AND that copies 1) bear this notice in full and 2) give the full citation on the first page. It is permissible to abstract these works so long as credit is given. To copy in all other cases or to republish or to post on a server or to redistribute to lists requires specific permission and payment of a fee. Contact Publisher@InformingScience.org to request redistribution permission. proviso that it was "difficult to pronounce in French"). Cailliau's anecdote illustrates many of the influences that affect the coining of names and terms by Information Communication Technology practitioners, including its predominantly English language origins and its subtext of Western culture. It also gives a rare insight to, and acknowledgement of, the processes employed in building a 
lexis to carry the communicative requirements of a new discipline.

As young men engaged in an evolving enterprise, and given the prevalence of Greek gods and goddesses (and their Roman equivalents) in the nomenclature of many existing (and less flexible) scientific disciplines, Cailliau's and Berners-Lee's reluctance to draw on classical Greek mythology was understandable. Cailliau and Berners-Lee also had the advantage, enjoyed by others working in ICT's, of functioning in an enterprise which was relatively unstructured and unconstrained by generations of practice.

\section{Lexical Constraints}

The freedom in creating naming systems enjoyed by ICT practitioners can be illustrated by comparing it with the historical constraints operating on those working in a discipline such as astronomy. For instance, an examination of the nomenclature of our solar system reveals the Earth to be the only planet not named after either a Roman or Greek god or goddess. This is a result of the planet names of Venus, Mars, Mercury, Jupiter and Saturn having been assigned by the citizens of ancient Greece and Rome for the planets' perceived likenesses to the deities. The beautiful goddess Venus gave her name to the bright planet, and the god of war Mars, to the red planet and so on (Carter, 2002). Once this convention was established, the naming of particular celestial bodies discovered later (such as the planets Uranus and Neptune and the [now] dwarf planet Pluto) was constrained by notions of consistency and enforced by bodies such as the International Astronomical Union (IAU).

While the name choice has now broadened beyond Greco-Roman gods and goddesses, the IAU continues to regulate the lexis assigned to significant new heavenly objects. Thus, when James Christy discovered Pluto's moon in 1978 and wanted to name it after his wife Charlene, he was refused permission by the IAU. The closest he came was by choosing Charon, the Greek mythological ferryman of the dead, whose name, when given an English pronunciation, is phonemically similar to the first syllable of his wife's name. Charon is also appropriate (in IAU terms) in that Charon served as ferryman to Pluto, the god of the Underworld (Carter, 2002). Even objects identified and named more recently, such as Sedna - the most distant known object in the solar system (discovered in 2004) (Brown, n.d.) and Quaoar, a Kuiper Belt object found in 2002 (Trujillo, n.d.) retain the IAU approved mythological theme. Sedna is named after an Innuit god and Quaoar after a North American god.

\section{Semantic Extensions}

Despite Cailliau's and Berners-Lee's antipathy, the lure of the lexis of the Greek myth remains strong in the ICT lexicon. Such lexis have continued to prove popular where the mythic material suggests the function of the task, such as in the operating systems of Oracle and Delphi. In Greek myth, it was to the prescient Greek Oracle living in a cave in Delphi that the troubled turned for guidance, just as the operating systems are intended to smooth the path ahead. Similarly, a Trojan horse (a malicious program designed to look like legitimate software) effectively carries with it the original mythic notion of an unsuspected and deadly attack.

The portal is another term that extends its meaning as a result of earlier mythic usage. While portals take researchers to other domains of data, the use of portals in myth is far more complex. In creation myths, the passing of portals has immense consequences for humankind — as in Adam and Eve's expulsion from their carefree existence in the Garden of Eden into the world of suffering (unleashing the world's woes upon their descendants), and in the carrying away of Persephone by Pluto into the Underworld (leaving a legacy of cold and sunless months each year). In its most general sense a portal is just a gate (from the Latin porta) (Skeat, 1983, p. 403). However, when heroes pass through literal or metaphorical portals in works of myth and fantasy, they enter 
strange and dangerous landscapes of physical and psychological testing, or as the mythologer Joseph Campbell describes it, the "fateful region of both treasure and danger" (1993, p. 58).

Their journeys are very different to those of researchers, but both pass through portals in search of information relevant to their purposes. The ability to fully engage with these words and terms, and to recognise and understand their subtext, is reliant on a high level of understanding of the English language and Western literary culture. For ICT practitioners who have spurned mythology, the absence of any over-arching governing organization which functions in a similar way to the IAU, has allowed for a range of creative nomenclature to come into existence. Some practitioners have chosen to immortalise themselves and/or their loved ones. Debian - a linux distribution, is a portmanteau of the names of its creator - Ian Murdock and his then girl friend, (now wife) (Debra). Likewise, awk - a computer pattern /action language, is an acronym of its developers' last names: $\underline{\text { Aho, }}$ Weinberger and Kernighan ("List of computer term etymologies." n.d.). Other ICT practitioners have coined or adopted a lexis with a humorous or larrikin edge. The founders of Yahoo! took the name from Swift's Gulliver's Travels $(1726 / 1969$, p. 260) where it referred to a repulsive, barely human creature.

A quick scan of the Web's Wikipedia reveals others. Google began as "googol", a tongue-incheek boast about the quantity the search engine would be able to search (a googol is a very large number - 1 followed by 100 zeros); Sosumi (so-sue-me) —a system sound in Apple Computer's System 7 operating system, dryly reflected the company's long history of litigation with Apple Records; and the web browser Mozilla, is a portmanteau of Mosaic-Killer (it replaced the Mosaic browser) and Godzilla (a cinematic monster). Wikipedia even cites itself as being named for the "wiki wiki" or fast shuttle buses at Honolulu Airport (List of computer term etymologies, n.d.). The fact that Wikipedia is one of the few places where information on the origins of ICT terminology is readily accessible, underscores the lack of focus on naming conventions. This in turn suggests a certain playfulness and lack of seriousness both by the coiners of names and their recorders.

\section{Phonetic Appeal}

A characteristic of many of these newly coined ICT terms is their catchiness (at least in English), a quality that Cailliau was also keen to see in the nomenclature of the World Wide Web. But what is catchiness? What makes one word or term more attractive, or more memorable than another? Little analysis of the term World Wide Web is necessary to identify its most salient feature of alliteration. In its simplest form, alliteration is the "repetition of the same sounds - usually initial consonants of words or of stressed syllables - in any sequence of neighbouring words" (Baldick, 1991, p. :5). It is achieved in this term by the identical initial sounds (graphically represented by 'w') in all three words, and by the identical final sound (represented by 'd') of the first two words. In addition, the sounds represented by ' $d$ ' and ' $b$ ' in the final two words, are similar.

While alliteration aids pronunciation, so too does the consistent consonant-vowel order across all three words. Consider the alliterative qualities of "frosts and fogs", a word combination liable to trick the tongue into saying "frosts and frogs". The repetition of the same sounds in words is easier to pronounce than changes in patterns, a preference illustrated by the coining of nonsensical reduplicatives such as easy-peasy and teeny-weeny. As well, sound repetitions, whether used alliteratively or as rhymes, serve as mnemonics, aiding user recall. The denotation and connotations of a word or term are also important. Denotations do not remain constant over time or space, 'queer' and 'gay' being contemporary examples of words that have enlarged their meanings to the point where earlier meanings have been largely subsumed. While the denotation of 'World Wide' has remained constant, 'web' now links strongly (it could be argued more strongly with particular generations) to a computational denotation, rather than to its earlier meanings. The connotations of 'web', at the time of Berners-Lee's adoption of it, were charming and organic (spiders' webs, 
the webby feet of ducks), and may have contributed to the "catching(ness)" Cailliau describes. As far as we know, Berners-Lee didn't engage in these analytical processes consciously, and it's not possible to say whether he did so unconsciously, though the attractiveness of alliteration suggests it.

The sound of a word is likewise important in deciding on its 'rightness' for the new phenomenon it seeks to describe. Onomatopoeic words mimic the phenomena they describe closely (chicks cheep; dogs woof) and non-onomatopoeic words can also carry a sound match that seems 'right'. Widget (an interface component) was a word adopted from the 1924 play, Beggar on Horseback, where it describes a mass-produced object (which was never identified) but which represented a "purely mercantile commodity that has no artistic or spiritual value" (GUI widget, n.d.). The second syllable represented by 'get', echoes the more common word 'gadget', and so carries with it the semantic connotations of that word. It is likely that widget is more generally known now as an ICT term than as the undefined but soulless object in the 1924 play.

\section{Crossing Cultures}

What is embraced or tolerated in Western culture as 'playful' or 'quirky' can pose subtle acceptance and/or comprehension barriers in other cultures both as surface and subtext. Amongst the most comprehensive research undertaken in identifying and measuring the impact of cultural difference is that carried out by Hofstede and his collaborators (Hofstede, 1980, 1991, 1994, 2001; Hofstede \& Bond, 1988), and Trompenaars and Hampden-Turner (1997). Both bodies of research identify dimensions by which cultures can be compared. While these dimensions have been applied extensively in the business sphere, Jones and Alony (2007) have critically reviewed their implications for Information Systems (IS). As expected, the available research suggests that cultural differences, as measured by the dimensions identified by Hofstede, Trompenaars and others, do have significant effects on how various ICT terms are viewed and used.

Two of Hofstede's dimensions are particularly relevant: Power Distance (PD) and Uncertainty Avoidance (UA). PD refers to how tolerant people are of wide differences between the various ranks in an organisation, and UA describes the extent to which people feel threatened by uncertain or unknown situations. These differences can emerge in a number of ways. For instance, a website from a culture with a high PD (where people are tolerant of wide disparities in rank) might focus on symbols of power, whereas a website from a low PD culture, might be far less status conscious, choosing instead to show how lower status groups might be empowered. In this context, some of the more irreverent ICT nomenclature might be unsuitable for a high PD culture. Similarly, people from cultures with high uncertainty avoidance, who tend to be uneasy in situations that they consider to be unclear, unstructured and unpredictable, are likely to be less at ease with a lexis that is subject to rapid and/or apparently random change.

While Jones and Alony acknowledge that Hofstede's work is not without its critics, they note that "it remains one of the most widely used pieces of research among scholars and practitioners" and that their overview "illustrates the importance of culture, and the impact each of Hofstede's dimensions has on IS design, development and management" (Jones \& Alony, 2007, p. 416).

\section{Moderating Lexical Meaning}

O'Grady et al. point out that some "systematic constraints" are essential in language creation if meaning is to be maintained, noting that "If well-established words were constantly being replaced by new creations, the vocabulary of English would be so unstable that communication could be jeopardised" (1996, p.3). While this is a consideration in a new discipline, as long as neologisms remain relatively small in number, they are no more difficult to assimilate by practitioners than other discipline-specific words-be they classed as meta-language or jargon. The 
randomness and lack of coherence in the terminology of ICT nomenclature however, does have the potential to affect the understanding of users expecting consistency (as noted earlier) - even if the user is an English as a first language speaker. In addition, the cultural specificity of some names (Charon being an Underworld associate of Pluto; Delphi being the place where the Oracle was located) potentially creates a further barrier to full comprehension by those who share the language but not the cultural knowledge and understanding.

There is a further aspect to choosing mythic (particularly Greek) nomenclature, which needs to be addressed. In discussing news media, Veronika Koller notes that, "By favouring particular metaphors in discourse, journalists can reinforce, or even create, particular mental models in their readers' cognition" (2004, p.3). Ancient Greek and Roman civilizations have long served as metaphors for high learning in both the rational and creative arts in the West, and when lexis from these eras is assigned elsewhere, it carries this metaphorical dimension with it. In disciplines like astronomy, which has a long and venerable history, such metaphorical transference serves to reinforce its status, but in new disciplines, such as ICT, such transference has the potential to build status, even in cultures with a low tolerance to Power Distance. This can occur obviously, with the surface features of text, but also subtly through the connotations of subtext.

The prestige that any language carries with it, whether specifically within ICT language use or more broadly, is an issue explored by Betsy Hu Xiao Qiong in her paper on China English (2004). She defines China English as being as "good a communicative tool as standard English", with pronunciation close enough to Standard English "not to pose much of a problem", with some "syntactic and grammatical differences attributable to the influence of Chinese" and occasional variation in lexis "reflecting cultural differences" (p. 28). Hu Xiao Qiong's sometimes passionate plea, that China English be accepted as a legitimate form of English, and used in China, is very much about the validation of culture. She notes that "Both in old China and new China, there are many things that are unique, for which English equivalents cannot be found" (p. 31), that courses in Chinese literature and Chinese politics should be conducted "in an English which reflects our culture" (p. 31), and questions why "a native-speaker standard should be imposed upon learners of English, when most of its speakers are in fact learning English as a second or foreign language" (p. 29). Hu Xiao Qiong's plea for an acceptance of China English reinforces the point that language serves as a powerful constructor of status.

David Crystal notes that: "as the Internet comes increasingly to be viewed from a social perspective, so the role of language becomes central" (2001, p. viii). In ICT's, this medium has historically been English. In discussing the link between the English language and status, Alastair Pennycook suggests that there is a "complex set of relationships between English and what types of culture and knowledge are given international credibility" (1994, p. 21), a notion reflected in Hu Xiao Qiong's support for China English. It is a set of relationships, Pennycook and others are critical of. He goes on to say: "Access to prestigious but often inappropriate forms of knowledge is often only through English, and thus, given the status of English both within and between countries, there is often a reciprocal reinforcement of the position of English and the position of imported forms of culture and knowledge" (1994, p. 21). There is also an obvious consequence for the mother-tongue(s) of the nations affected.

\section{Beyond English}

In discussing the Internet, Crystal notes that "what is immediately obvious when engaging in the any of the Internet's functions is its linguistic character. If the Internet is a revolution, therefore, it is likely to be a linguistic revolution" (2006, p. x). Hu Xiao Qiong raises the question as to the exact nature of this "linguistic revolution" when she suggests that "it is likely that China English will become the variety of English spoken by the largest number of people in the world" (2004, p. 31). If this becomes the case, one would expect a flow of China English onto the Internet. In a 
broad ranging overview, Crystal notes that while the web was originally a "totally English medium" (due to its US origins), the impression that this continues to be the case is inaccurate (2006, p. 229-230). Nearly ten years ago, the total number of newly created non-English Web sites had already surpassed the total of newly created English Web sites (Lebert, 1999).

According to Crystal, the Web is "increasingly reflecting the distribution of language presence in the real world" (2006, p. 231), and that "Most sources expect Chinese to be the majority language of Internet users by 2007" (p. 231). But mere presence on the Internet does not guarantee linguistic dominance. As he goes on to say, "Until a critical mass of Internet penetration in a country builds up, and a corresponding mass of content exists in the local language, the motivation to switch from English language sites will be limited to those for whom issues of identity outweigh issues of information" (p. 233). Critical mass is important, because, in Crystal's words: "a single language site is useless because the owner has no one to link to" (p. 233).

\section{Conclusion}

The language of ICT continues to evolve, generating a lexis operating both linguistically and metalinguistically, operating and informing both through surface features and through subtext. Blogging and instant messaging creates a lexis that both describes the process and the participant. Blogging for instance, is carried out by a blogger or blogster using an ICT language that is, in some ways, totally new. Crystal (2006) describes it as a "variety of writing intended for public consumption which appears exactly as the author wrote it, which is not constrained by other genre conventions, and which privileges linguistic idiosyncrasy" (p. 246). In addition, Instant Messaging has the capacity to enlarge the lexis from conventional letter symbols to emoticons, avatars, and audio and visual elements, in order to carry the communicative message.

The particularities of how these innovations are being used and adapted by diverse language and cultural groups, and will be used and adapted, remains the province of future research. However, in finishing, it is useful to return to the words of one of the Web's developers, Tim Berners-Lee (1999), who notes that "The Web is more a social creation than a technical one" (p. 133) and that "the dream of people-to-people communication through shared knowledge must be possible for groups of all sizes, interacting electronically with as much ease as they do now in person" (p. 169). Bearing this in mind, the importance of clear communication, incorporating shared understanding of meaning, can only grow as technologies continue to develop.

\section{References}

Baldick, C. (1991). The concise Oxford dictionary of literary terms. Oxford: Oxford University Press.

Berners-Lee, T. (1999). Weaving the Web. London: Orion Business Books.

Brown, M. (n.d.). Sedna. Retrieved September, 2006 from: http://www.gps.caltech.edu/ mbrown/sedna

Cailliau, R. (1995). A short history of the Web. [Speech presented at the launching of the European Consortium, Paris, 2 November 1995]. Retrieved September, 2006 from: http://www.netvalley.com/archives/mirrors/robert_cailliau_speech.htm

Campbell, J. (1993). The hero with a thousand faces. London: HarperCollins.

Carter, L. (2002). Curious about astronomy? Retrieved September, 2006 from: http://curious.astro.cornell.edu/question.php/number $=372$

Crystal, D. (2006). Language and the Internet (2nd ed.). Cambridge: Cambridge University Press.

GUI widget. (n.d.) Wikipedia. Retrieved from http://en.wikipedia.org/wiki/Widget_(computing)

Hofstede, G. (1980). Culture's consequences: International differences in work-related values. CA: Sage. 
Hofstede, G. (1991). Culture and organizations. London: HarperCollins.

Hofstede, G. (1994). The business of international business is culture. International Business Review, 3(1).

Hofstede, G. (2001). Cultures, consequences, comparing values, behaviours, institutions, and organizations across nations (2nd ed.). CA: Sage.

Hofstede, G., \& Bond, M.H. (1988). The Confucius connection: From cultural roots to economic growth. Organizational Dynamics, 16(4).

Hu Xiao Qiong, B. (2004). Why China English should stand alongside British, American, and the other 'world Englishes'. English Today, 20 (2 April), 26-33.

Jones, M., \& Alony, I. (2007). The cultural impact of Information Systems - through the eyes of Hofstede - a critical journey. Issues in Informing Science and Information Technology, 4, 407-419. Retrieved from http://proceedings.informingscience.org/InSITE2007/IISITv4p407-419Jone365.pdf

Koller, V. (2004). Metaphor and gender in business media discourse: A critical cognitive study. New York: Palgrave Macmillan.

Lebert, M-F. (1999). Le multilinguisme sur le Web. Retrieved from: http://www.cveil.qc.ca/multieng2.htm

List of computer term etymologies. (n.d.) Wikipedia. Retrieved from http://en.wikipedia.org/wiki/List of computer term etymologies

O'Grady, W., Dobrovolsky, M., \& Katamba, F. (1997). Contemporary linguistics: An introduction. Harlow, U.K: Longman.

Pennycook, A. (1994). The cultural politics of English as an international language. Harlow, U.K: Pearson Education.

Skeat, W. (1983). Concise etymological dictionary of the English language. Oxford: Oxford University Press.

Swift, J. (1969). Gulliver's travels. New York: Random House. (Original work published 1726.)

Trompenaars, F., \& Hampden-Turner, C. (1997). Riding the waves of culture: Understanding cultural diversity in business (2nd ed.). London: Nicholas Brealey.

Trujillo, C. (n.d.). Frequently asked questions about Quaoar. Retrieved September, 2006 from: http://www.gps.caltech.edu/ chad/quaoar/

\section{Biography}

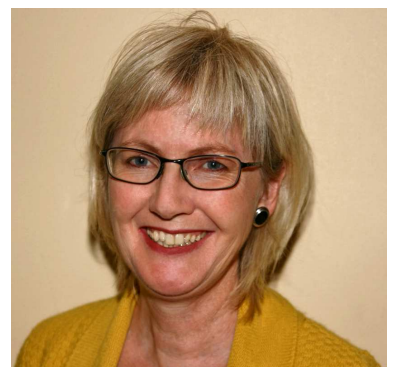

Dr Karen Simpson Nikakis has pursued her interest in language and writing through careers in Secondary Education, Vocational Education and Training, Adult Migrant Education and in the University sector. Her research interests reflect her present role as a lecturer in Business Communications at Deakin University and, as a fantasy novelist with the publishers Allen and Unwin. As well as exploring creative subtexts in business and technological writing, Karen is completing the editing of Book 2 in The Kira Chronicles trilogy (www.kirachronicles.com.au) 